\title{
Oral Health Status among Older Adults Attending Public Clinics in Khartoum State, Sudan: a cross- sectional study
}

Mayson Salih ( Maysonsalih@ust.edu.sd)

University of Science and Technology Omdurman

Raouf Ali

University of Science and Technology Omdurman

Elwalid Nasir

King Faisal University, Alahsa

\section{Research Article}

Keywords: Oral health, older adults, (DMFT), prosthetic needs, Sudan

Posted Date: January 6th, 2021

DOl: https://doi.org/10.21203/rs.3.rs-137092/v1

License: (c) (1) This work is licensed under a Creative Commons Attribution 4.0 International License.

Read Full License 


\section{Abstract \\ Background}

As the number of older adults is growing worldwide, understanding the extension of the oral health problems of the older population is important for the determination of treatment needs and for future planning of dental services. This study assessed the oral health status and prosthetic needs among a group of older adults living in Khartoum State, Sudan.

\section{Methods}

A cross sectional study among individuals $\geq 60$ years attending Health Care Centers. The clinical examination was based on the WHO oral health examination form for adults, 2013, which includes dentition status, periodontal conditions, oral mucosal lesions, tooth wear, prosthetic status and prosthetic needs.

\section{Results}

249 older adults participated in the study, $64.3 \%$ were males and the mean age was 68.4 years (SD \pm 6.7$)$. The mean (DMFT) was 15.9 (SD \pm 9.1 ), with $85.3 \%, 94.8 \%$, and $19.3 \%$ of the participants had decayed, missed or filled teeth, respectively. Periodontal pockets were present in $41.9 \%$ of the participants and attachment loss was in $84.2 \%$. Only $14.9 \%$ had mucosal lesions while $46.2 \%$ showed signs of tooth wear. Although only $5.2 \%$ were completely edentulous, $93.2 \%$ of the participants need at least one unit prosthesis while only $10 \%$ had removable dentures. The main predicting factors of poor oral health were being female, poor oral hygiene practices, frequency and reason of dental visits, and poor perceived poor oral health.

\section{Conclusion}

Despite the low level of edentulism, the oral health of older adults of the studied Sudanese population was poor. They showed high prevalence and severity of missed and decayed teeth, periodontal disease and high prosthetic treatment needs.

\section{Background}

As the proportion of older adults ( $\geq 60$ years) (1) is growing faster than any other age group worldwide, the changes in disease patterns associated with ageing increase the challenges during health policy planning (2). Oral health is an important component of the World Health Organization (WHO) policy "Active Ageing" (3) which outlines the essential approaches towards healthy ageing. The policy 
necessitates investigating the impact of oral health on the general health and quality of life of elderly people (3).

Many studies worldwide associated ageing with poor oral health. In some previous studies, poor oral health was demonstrated as high prevalence of coronal and root caries (4), tooth loss and edentulousness $(5,6)$, periodontal diseases, reduced salivary flow $(7)$, oral mucosal lesions and tooth wear (8). Moreover, poor oral health, missing teeth and reduced masticatory efficiency were also associated with nutritional deficit $(9,10)$, weight loss and reduced cognitive functions $(11,12)$, increased probability of frailty $(13)$ and increased odds of mortality $(14,15)$. Periodontal diseases were also associated with diabetes mellitus, ischemic heart diseases and chronic respiratory diseases (16).

Although there is a growing evidence that old adults are at a greater risk for oral diseases, many older adults experience significant barriers to obtain necessary dental care $(17,18)$. The availability of dental service in developing countries is very low compared to treatment needs among adults and elderly (19). Moreover, oral health inequality is evident between different socioeconomic groups, healthy and unhealthy individuals and with different levels of dependency (20).

Sudan is the third largest country in the African continent with an estimated total population (in 2019) of $42,813,000$ (21). Khartoum State (the capital of Sudan) has an estimated population of 5,678,000 (22). The Central Bureau of Statistics, Sudan, 2018 estimated the number of $\geq 60$-year-old population in Khartoum State as 429,780 forming (5.37\%) of the total population (22). The oral health of the Sudanese elderly population has been evaluated as a part of an oral health survey in Sudanese population (23). The results revealed high levels of oral diseases within this age group. Understanding the extension of the oral health problems of the older population is important for estimation of treatment needs and the future planning of dental services. This study aimed to assess the oral health status and prosthetic needs among older adults living in Khartoum State, Sudan.

\section{Methods}

Study sample: This hospital-based cross sectional study is a part of a research project that investigated the oral health status, oral functions, physical and cognitive functions as well as the oral health related quality of life. The study was conducted at the outpatient clinics in Health Care Centers. Fourteen centers, two from each locality, were randomly selected from a list of all health centers in the state. The sample size was calculated using the formula: $\left(n=[\operatorname{DEFF} N \mathrm{~Np}(1-\mathrm{p})] /\left[\left(\mathrm{d}^{2} / \mathrm{Z}^{2}{ }_{1-\mathrm{a} / 2}{ }^{*}(\mathrm{~N}-1)+\mathrm{p}^{\star}(1-\mathrm{p})\right]\right)\right.$ in $5 \%$ precision at $95 \% \mathrm{Cl}, 1.5$ as design effect and $87.7 \%$ prevalence of dental caries among Sudanese adults (23). The calculation gave a sample size of 249 older adults. The sample size was distributed proportionally among the seven localities per the population. All patients, co-patients and employee who were $\geq 60$-yearold in the selected Health Care Centers were invited to participate in the study fulfilling the desired number from each center. Ethical approval was obtained from the University of Science and Technology (UST), Omdurman, Sudan and the Management of Innovation, Development and Scientific Research, Ministry of Loading [MathJax]/jax/output/CommonHTML/jax.js ponsent form before the beginning of the data collection. 


\section{Data collection}

Data were collected through an interview and a clinical examination. An Arabic version of the (WHO) oral health questionnaire was used. The questionnaire included the patient's age, sex, sociodemographic status, oral and general condition, medications, oral hygiene practices, frequency and reasons of dental visit (Table 1).

Table 1

Components of the data collection tools.

\begin{tabular}{|c|c|}
\hline Factors & Components \\
\hline Age & Age groups (60-69, 70 and above) \\
\hline $\begin{array}{l}\text { Socioeconomic status } \\
\text { (Low/High) }\end{array}$ & Educational level, occupation, monthly income. \\
\hline $\begin{array}{l}\text { Tobacco consumption } \\
\text { (No/Yes) }\end{array}$ & Smoking, smokeless tobacco use \\
\hline $\begin{array}{l}\text { Oral hygiene } \\
\text { (Inadequate/ Adequate) }\end{array}$ & Frequency of brushing, tools and tooth paste \\
\hline $\begin{array}{l}\text { General health } \\
\text { (Poor/Good) }\end{array}$ & Chronic conditions, medications and BMI \\
\hline $\begin{array}{l}\text { Perceived oral health } \\
\text { (Poor/Good) }\end{array}$ & $\begin{array}{l}\text { Pain in the last } 12 \text { months, patients' description to teeth and gum status, } \\
\text { number of reported teeth in the mouth. }\end{array}$ \\
\hline \multirow{2}{*}{$\begin{array}{l}\text { Utilization of dental } \\
\text { services }\end{array}$} & Last dental visit ( $\leq 1$ year/ $>1$ year) \\
\hline & Reason of last visit (Pain/Routine) \\
\hline
\end{tabular}

The clinical examination was based on the (WHO) oral health examination form for adults 2013(24). Dentition status (crown and roots) were recorded as Decayed (D), Missed (M), and Filled (F) Teeth then the (DMFT) score was calculated for each patient. Also, the mean number of the affected teeth/participant, as well as the severity of the dental conditions among the affected participants as low or high using the mean as the cut-off point.

The modified Community Periodontal Index (CPI) was used to evaluate the periodontal status through evaluation of gingival bleeding and measuring the periodontal pocket depth for all teeth using a WHO (CPI) probe. In addition, the number of the affected teeth was calculated for bleeding on probing and the mean was used as a cutoff point to classify the severity of the condition (low or high). The attachment loss was measured for six index teeth; 17/16, 11, 26/27, 37/36, 31 and 46/47. Periodontal examination was performed in $81.5 \%$ (203) participants, while 46 were excluded (13 edentulous and 33 either refused the examination or excluded due to their general health condition).

Tooth wear was recorded per the severity of the condition (no sign of wear, enamel lesion, dentinal lesion, or nuln inunlunmannt) and thn numbnr of tanth involved. Examination of the oral cavity was carried out in Loading [MathJax]/jax/output/CommonHTML/jax.js 
orderly manner to detect for oral mucosal lesions.

Only subjects who were wearing or could show their dentures at the examination were recorded as denture-wearers. Denture status was recorded for each jaw as: no denture, partial denture, or complete denture. The prosthetic needs were also recorded for each jaw as: no prosthesis needed, need for one unit prosthesis, need for multi-unit prosthesis, need for combination of one and/or multi-unit prosthesis, or need for full prosthesis.

Two dentists examined all participants. The examiners first practiced the examination procedure on a group of 10 subjects before the start of data collection, and then re-examined them after one-week time to assess the inter-examiners reliability. Duplicate examination of $10 \%$ of the study sample was done at the beginning, mid-way and at the end of the data collection to confirm inter-examiner reliability. Intra-class correlation coefficient (ICC) was used to measure inter-examiner reliability for (DMFT). ICC for (DMFT) was 0.98 (95\% $\mathrm{Cl} 0.92-0.96), 0.92$ (95\% $\mathrm{Cl} 0.44-0.99)$ and 0.92 (95\% $\mathrm{Cl} 0.57-0.99)$ at the beginning, mid-way and at the end of the study. Kappa was used to determine the inter-examiner reliability for periodontal attachment loss and prosthetic need. Kappa for attachment loss and prosthetic needs were 0.58 and $0.83,0.5$ and 0.66 , and 0.44 and 1 at the beginning, mid-and at the end of the study, respectively.

Statistical analysis: Descriptive statistics (frequency and mean \pm SD) were used for univariate analysis. Chi square test and Fissure exact test were used for bivariate analysis phase. In the multivariate analysis level, multiple logistic regressions models were used to investigate the effect of independent variables on components of oral health status. The independent variables were entered in the model in three steps: step 1; biological factors (age and gender), step 2; personal factors (socioeconomic status, tobacco use and general health) and step 3; oral health behaviours (oral hygiene practises, perceived oral health, frequency of dental visits and reason of dental visit). Odds Ratios (OR) and Confidence Interval (Cl) of $95 \%$ were reported, and $p$-Value $<0.05$ was considered as statistically significant.

\section{Results}

Two hundred forty-nine individuals participated in the study, $64.3 \%$ were males, and $62.7 \%$ were between 60-69-year-old with the mean age of 68.24 years ( $S D \pm 6.7$, range 60-95 years). About one third of the participants had no formal education, while $34.5 \%$ were retired. The mean monthly income was 2596 Sudanese Pound (SD \pm 2951.15 ) with the majority, $88.4 \%$ of the participants rated their monthly income as poor. The majority, $90.4 \%$, had at least one chronic disease, while $75.1 \%$ reported taking medications (Table 2). The reported oral hygiene practices, perceived oral health measures and frequency of dental visits are shown in (Table 3 ).

The mean (DMFT) was 15.9 (SD \pm 9.1 , range $0-32$ ), with $49 \%$ of the participants had high (DMFT). Majority of the participants, $94.8 \%$, had one or more missing teeth, $83.5 \%$ had decayed teeth, while only $19.3 \%$ had filled teeth. Most, $81.9 \%$, had decayed crowns and $40.6 \%$ had decayed roots with a mean of 3.7 (SD \pm 3.8 ) and $0.8(S D \pm 1.3)$, respectively. Few $18.9 \%$ had filled crowns, and only $2.8 \%$ had filled roots; 
the mean number of filled crowns and roots was 0.35 ( $S D \pm 0.91)$ and $0.03(S D \pm 0.19)$, respectively. Only $5.2 \%$ of the participants were fully dentate, $89.6 \%$ partially dentate and $5.2 \%$ were completely edentulous.

Majority of the participants, $96.1 \%$, had gingival bleeding, $41.9 \%$ had periodontal pockets, while $84.2 \%$ had loss of attachment. Oral mucosal lesions were observed in $14.9 \%$ of the participants, the most observed lesion was leukoplakia seen in $59.5 \%$ of the cases. Less than half, $43.2 \%$, of lesions were in the sulci, while $27 \%$ were in the alveolar ridge and gingiva.

Among the dentate participants, $79.5 \%$ showed tooth wear. Few, $17.3 \%$ of the participants reported that they have dentures but only $10 \%$ showed their dentures to the examiners, while majority of the participants $93.2 \%$ needed at least one unit prosthesis (Table 4). 
Table 2

Percentage distribution of

Sociodemographic and general health related characteristics.

\begin{tabular}{|ll|}
\hline Variable & $\%($ No) \\
\hline Age Groups & $62.7(156)$ \\
$60-69$ years & $37.3(93)$ \\
$\geq 70$ & \\
\hline Gender & $64.3(160)$ \\
Male & $35.7(89)$ \\
Female & \\
\hline Education Level & $67.5(168)$ \\
No/Poor education & $32.5(81)$ \\
Good/High education & \\
\hline Occupational Level & $30.5(76)$ \\
Unemployed & $69.5(173)$ \\
Employed & \\
\hline Monthly income & $88.4(220)$ \\
Poor & $11.6(29)$ \\
Good & $9.6(20)$ \\
\hline Socioeconomic Status & $64.7(161)$ \\
Low & $35.3(88)$ \\
High & $9.4(22)$ \\
\hline Habits & \\
Smoking & \\
Smokeless tobacco & $0.8(24)$ \\
Drinking alcohol & \\
\hline Chronic disease & \\
No & \\
Yes & \\
\hline
\end{tabular}




\begin{tabular}{|ll|}
\hline Variable & $\%$ (No) \\
\hline Medications & $24.9(62)$ \\
No & $75.1(187)$ \\
\hline BMI & \\
Under/overweight & $46.3(134)$ \\
Normal & \\
\hline General health & $83.1(207)$ \\
Poor & $16.9(42)$ \\
Good & \\
\hline
\end{tabular}


Table 3

Percentage distribution of oral hygiene practices and perceived oral health status

\begin{tabular}{|ll|}
\hline Variable & $\%(\mathrm{No})$ \\
\hline Frequency of teeth cleaning: & $2.8(7)$ \\
Less than once/day & $97.2(242)$ \\
\hline Once or twice/ day & \\
\hline Tools of teeth cleaning & $88.8(221)$ \\
Toothbrush & $33.2(82)$ \\
Interdental cleaning tools & $47.4(118)$ \\
\hline Traditional cleaning tools & \\
\hline Use of toothpaste & $8.5(21)$ \\
No & $91.5(225)$ \\
Yes & \\
\hline Use of fluoridated toothpaste & $55.8(136)$ \\
\hline No & $44.2(108)$ \\
Yes & \\
\hline Oral hygiene practice & $57.4(143)$ \\
Inadequate & $42.6(106)$ \\
Adequate & \\
\hline Pain or discomfort from teeth or mouth & $49(122)$ \\
\hline No & $51(127)$ \\
\hline Yes & $65.9(164)$ \\
\hline Perceived number of natural teeth & \\
\hline Pood & \\
\hline
\end{tabular}




\begin{tabular}{|ll|}
\hline Variable & $\%($ No) \\
\hline Perceived gum status & $11.2(28)$ \\
Good & $88.8(221)$ \\
\hline Perceived oral health & \\
Poor & $51.8(129)$ \\
Good & $48.2(120)$ \\
\hline Time since last dental visit & \\
\hline Never received dental treatment & $7.6(19)$ \\
One year or less & $37(92)$ \\
More than one year & $55.4(138)$ \\
\hline Reason of last dental visit & $72.6(167)$ \\
Pain or trouble with teeth, gums or mouth & $27.4(63)$ \\
Consultation /Treatment/ follow-up & \\
\hline
\end{tabular}


Table 4

Frequency and percentage distribution of clinical characteristics of oral health status

\begin{tabular}{|c|c|c|c|c|}
\hline Variable & $\%(\mathrm{No})$ & Mean ( \pm SD) & \multicolumn{2}{|c|}{ Severity of the condition \% (No) } \\
\hline Dentition status & - & $15.9( \pm 9.1)$ & \multicolumn{2}{|l|}{ High 49 (122) } \\
\hline (DMFT) & $\begin{array}{l}83.5 \\
(208)\end{array}$ & $4.2( \pm 4.1)$ & \multicolumn{2}{|l|}{ High 37.5 (78) } \\
\hline Decayed teeth & & $0.37( \pm 0.9)$ & \multicolumn{2}{|l|}{ High 50 (24) } \\
\hline Filled teeth & $19.3(48)$ & $11.4( \pm 8.9)$ & \multicolumn{2}{|l|}{ High 38.1 (90) } \\
\hline Missed teeth & $(236)$ & & & \\
\hline \multicolumn{5}{|c|}{ Periodontal condition $(n=203)$} \\
\hline Gingival bleeding & $\begin{array}{l}96.1 \\
(195)\end{array}$ & $\begin{array}{l}62.6 \%( \pm \\
30.4 \%)\end{array}$ & \multicolumn{2}{|l|}{ High 50.8\% (99) } \\
\hline \multirow[t]{2}{*}{ Periodontal pocket } & $41.9(85)$ & - & \multicolumn{2}{|l|}{$4-5 \mathrm{~mm} 68.2(58)$} \\
\hline & & & \multicolumn{2}{|l|}{$\geq 6 \mathrm{~mm} 31.8(27)$} \\
\hline \multirow{4}{*}{$\begin{array}{l}\text { Loss of } \\
\text { attachment }\end{array}$} & \multirow{4}{*}{$\begin{array}{l}84.2 \\
(165)\end{array}$} & - & \multirow{2}{*}{\multicolumn{2}{|c|}{$\begin{array}{l}4-5 \mathrm{~mm} 41.8(69) \\
6-8 \mathrm{~mm} 41.2(68)\end{array}$}} \\
\hline & & & & \\
\hline & & & \multicolumn{2}{|l|}{ 9-11 mm $6.7(11)$} \\
\hline & & & \multicolumn{2}{|l|}{$\geq 12$ mm 10.3 (17) } \\
\hline $\begin{array}{l}\text { Oral mucosal } \\
\text { lesion }\end{array}$ & $\begin{array}{l}85.1 \\
(212)\end{array}$ & - & & \\
\hline No & $14.9(37)$ & & & \\
\hline \multicolumn{5}{|l|}{ Yes } \\
\hline Tooth wear $(n=$ & $20.5(51)$ & $17.5(\mathrm{SD} \pm 8.8)$ & \multicolumn{2}{|c|}{ Enamel lesions 46.2 (84) } \\
\hline 然 & 79.5 & & \multicolumn{2}{|c|}{ Dentine lesions 39.6 (72) } \\
\hline TNO & & & \multirow{2}{*}{\multicolumn{2}{|c|}{ Pulp involvement 14.2 (26) }} \\
\hline res & $1.2(3)$ & & & \\
\hline \multicolumn{5}{|l|}{ No records } \\
\hline Prosthetic status & $90(224)$ & - & Upper & Lower \\
\hline No dentures & $10(25)$ & & Partial 52.3 (11) & Partial58.8(10) \\
\hline Dentures & & & Complete 47.6 (10) & Complete41.2(7) \\
\hline
\end{tabular}




\begin{tabular}{|lllll|}
\hline Variable & $\%($ No) & Mean $(\mathbf{\pm}$ SD) & Severity of the condition \% (No) \\
\hline Prosthetic need & $6.8(17)$ & - & Upper & Lower \\
No need & 93.2 & One unit12.5(25) & One unit11.1(23) \\
Need prosthesis & $(232)$ & & Multiunit10.1(20) & Multiunit 7.2(15) \\
& & Combination62.3 & Combination72.1 \\
& & $(124)$ & $(150)$ \\
& & Complete15.1(30) & Complete9.6(20) \\
\hline
\end{tabular}

Bivariate analysis and multivariate logistic regression models showed that the likelihood of having high mean (DMFT) increased with female $(p=0.004)$, good general health $(p=0.04)$, poor perceived oral health $(p<0.001)$, frequent dental visits $(p=0.01)$ for routine treatment and check-up $(p=0.009)$ (Table 5). 
Table 5

The presence and severity of Decayed, Filled and Missed teeth regressed among biological factors, personal factors and oral health behaviors.

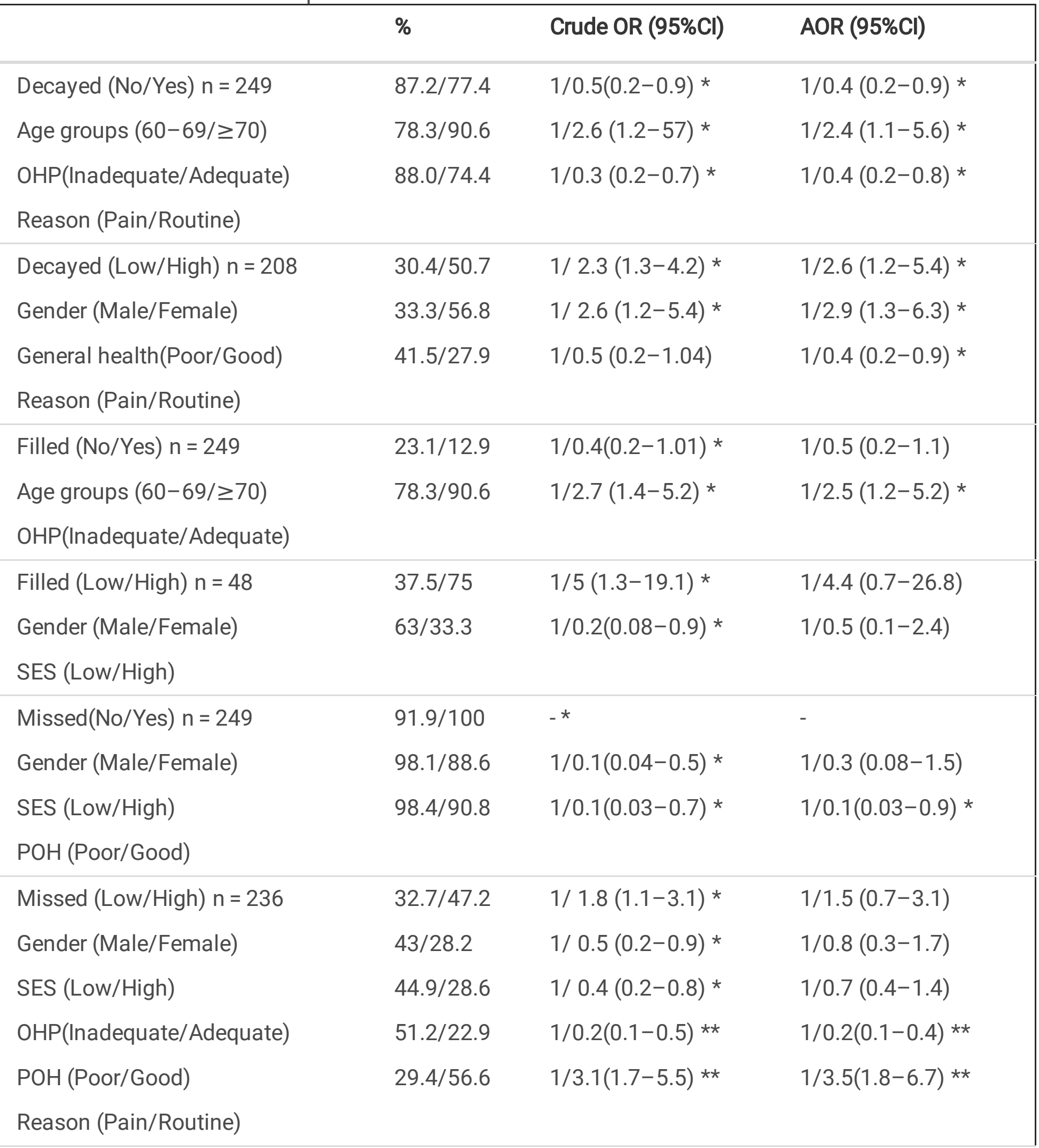

\begin{tabular}{|l|l|}
${ }^{*} p \leq 0.05,{ }^{*} p \leq 0.001$, SES: socioeconomic status, OHP: oral hygiene practice, $P O H:$ perceived oral \\
\hline Loading [MathJax]/jax/output/CommonHTML/jax.js
\end{tabular} 


\begin{tabular}{|c|c|c|c|}
\hline & $\%$ & Crude OR $(95 \% \mathrm{Cl})$ & AOR $(95 \% \mathrm{Cl})$ \\
\hline$(\mathrm{DMFT})($ Low $/$ High $) \mathrm{n}=249$ & $40 / 65.2$ & $1 / 2.8(1.6-4.8) \star \star$ & $1 / 2.6(1.3-5.2)$ * \\
\hline Gender (Male/Female) & $54.7 / 38.6$ & $1 / 0.5(0.3-0.8)$ * & $1 / 1.04(0.5-2.03)$ \\
\hline SES (Low/High) & $46.4 / 61.9$ & $1 / 1.8(0.9-3.7)$ & $1 / 2.1(1.02-4.6)$ * \\
\hline General health(Poor/Good) & $55.9 / 39.6$ & $1 / 0.5(0.3-0.8)$ * & $1 / 0.8(0.4-1.5)$ \\
\hline $\mathrm{OHP}$ (Inadequate/Adequate) & $62 / 35$ & $1 / 0.3(0.2-0.5) * \star$ & $1 / 0.3(0.1-0.5)$ ** \\
\hline $\mathrm{POH}$ (Poor/Good) & $59.8 / 42.7$ & $1 / 0.5(0.2-0.8) *$ & $1 / 0.4(0.2-0.8)$ * \\
\hline Dental visit ( $\leq 1 />1$ year) & $43.1 / 61.0$ & $1 / 2.1(1.2-3.5) *$ & $1 / 2.2(1.2-4.1)$ * \\
\hline \multicolumn{4}{|l|}{ Reason (Pain/Routine) } \\
\hline
\end{tabular}

The prevalence and severity of periodontal conditions showed no statistically significant relation with the explanatory factors except of an increase in the prevalence of loss of attachment in the older age groups $(p=0.04)$. Participants with poor perceived oral health appeared to have higher odds of pockets $\geq 6 \mathrm{~mm}$ $(p=0.04)$ and attachment loss of $\geq 6 \mathrm{~mm}(p=0.04)$. In the multivariate logistic model the odds of having mucosal lesions were increased in participants using tobacco $(p=0.008)$ and poor general health $(p=$ $0.03)$. Individuals with high socioeconomic status had less tooth wear $(p=0.005)$, while participants with poor perceived oral health presenting higher odds of having pulp involvement of tooth wear $(p<0.001)$ (Table 6). 
Table 6

the presence and severity of periodontal conditions, oral mucosal lesions and tooth wear regressed among biological factors, personal factors and oral health behaviors.

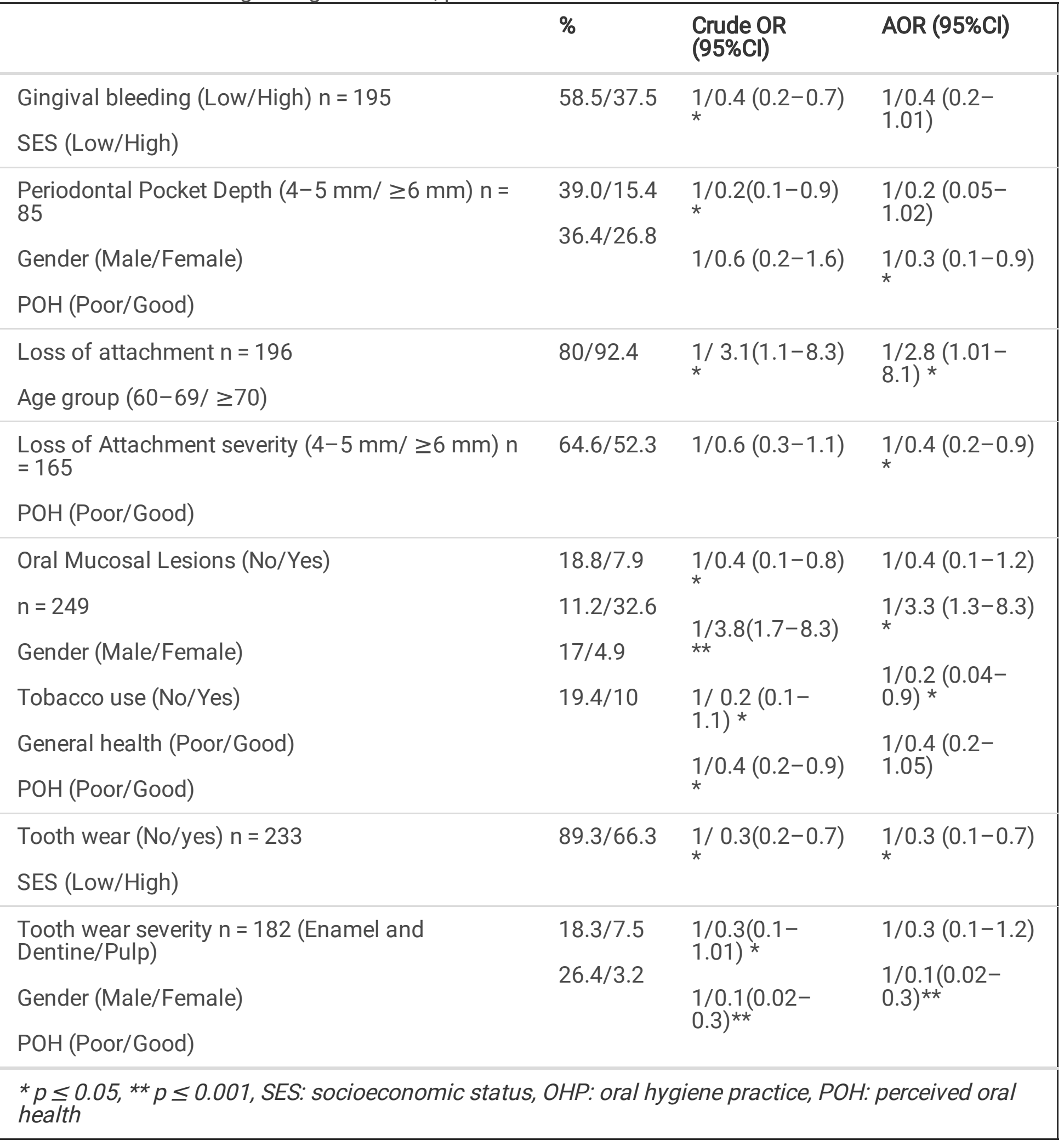

The odds of having removable dentures increased significantly among participants with poor perceived oral health $(p=0.01)$, and those visited dentists regularly $(p=0.02)$ for routine check-up and treatment ( $p$ $<0.001)$. Being a female $(p=0.04)$, participants with poor perceived oral health $(p=0.007)$, those who Loading [MathJax]/jax/output/CommonHTML/jax.js tt $(p=0.03)$, and inadequate oral hygiene practices $(p=0.02)$ 
appeared to be associated with high prosthetic need. While the odds of complete denture treatment needs increased significantly in females $(p=0.007)$, participants with inadequate oral hygiene practices $(p=$ $0.003)$, poor perceived oral health $(p=0.01)$ and visiting dentist for routine check-up and treatment $(p<$ 0.001) (Table 7).

Table 7

The presence and severity of the prosthetic status and prosthetic need regressed among biological factors, personal factors and oral health behaviors.

\begin{tabular}{|c|c|c|c|}
\hline & $\%$ & Crude OR (95\%Cl) & AOR (Cl) \\
\hline Prosthetic status(No/Yes)n = 249 & $14 / 5.8$ & $1 / 0.3(0.1-0.9)$ * & $1 / 0.2(0.1-0.8) *$ \\
\hline $\mathrm{POH}($ Poor/Good) & $15.2 / 7.0$ & $1 / 0.4(0.1-0.9)$ * & $1 / 0.3(0.1-0.8)$ * \\
\hline Dental visit ( $\leq 1 />1$ year) & $4.8 / 20.7$ & $1 / 5.1(2.1-12.6)$ ** & $1 / 6.5(2.4-17.4)^{\star \star}$ \\
\hline \multicolumn{4}{|l|}{ Reason (Pain/Routine) } \\
\hline Prosthetic status (Partial/Complete) $n=25$ & $58.8 / 12.5$ & $1 / 0.1(0.01-1.01)$ * & $1 / 0.1(0.008-4.3)$ \\
\hline OHP(Inadequate/Adequate) & $12.5 / 58.8$ & $1 / 10(0.9-100.4)$ * & - \\
\hline \multicolumn{4}{|l|}{ Reason (Pain/Routine) } \\
\hline Prosthetic need(No/Yes) n = 249 & $90 / 98.9$ & $1 / 9.7(1.2-75)$ * & $1 / 9.6(1.1-89.1)^{*}$ \\
\hline Gender (Male/Female) & $95.9 / 87.5$ & $1 / 0.3(0.1-0.7)$ * & $1 / 0.3(0.09-1.3)$ \\
\hline SES (Low/High) & $91.6 / 95.3$ & $1 / 1.8(0.6-5.4)$ & $1 / 4.6(1.2-17.7)^{\star}$ \\
\hline OHP(Inadequate/Adequate) & $98.4 / 87.5$ & $1 / 0.1(0.02-0.5)$ * & $1 / 0.1(0.02-0.5)^{\star}$ \\
\hline $\mathrm{POH}($ Poor/Good) & $97.8 / 90.4$ & $1 / 0.2(0.04-0.9)$ * & $1 / 0.2(0.04-1.1)$ \\
\hline Dental visit $(\leq 1 />1$ year $)$ & $95.8 / 87.8$ & $1 / 0.3(0.1-0.8)$ * & $1 / 0.2(0.08-0.9) *$ \\
\hline \multicolumn{4}{|l|}{ Reason (Pain/Routine) } \\
\hline Prosthetic need (Partial/Complete) $n=232$ & $9.7 / 28.4$ & $1 / 3.6(1.7-7.5) * \star$ & $1 / 3.8(1.4-10.1)^{\star}$ \\
\hline Gender (Male/Female) & $26.7 / 4.0$ & $1 / 0.1(0.03-0.3) * \star$ & $1 / 0.1(0.05-0.5)^{\star}$ \\
\hline OHP(Inadequate/Adequate) & $22.0 / 10.5$ & $1 / 0.4(0.1-0.8)$ * & $1 / 0.3(0.1-0.8)$ * \\
\hline $\mathrm{POH}($ Poor/Good) & 23.3/12.7 & $1 / 0.4(0.2-0.9)$ * & $1 / 0.4(0.1-1.01)$ \\
\hline Dental visit ( $\leq 1 />1$ year) & $9.4 / 33.3$ & $1 / 4.8(2.3-9.9)$ ** & $1 / 4.7(2.1-10.9)^{\star \star}$ \\
\hline Reason (Pain/Routine) & & & \\
\hline
\end{tabular}


The aim of this study was to assess the oral health status and prosthetic treatment needs among older adults living in Khartoum state. The male: female ratio and distribution of age groups in the study are largely compatible with the estimated $55 \%$ males and $58.4 \%$ aging between $60-69$ years of the $\geq 60$ years population of Khartoum state (22). The reported current smokers, smokeless tobacco users, alcohol consumers, those having chronic diseases and BMI-score were comparable to that reported in Sudan STEPwise survey 2016 (25).

The reported (DMFT) in this study (15.9) was relatively lower compared to that reported worldwide: 20.3 $( \pm 9.0$ ) in Belgium (26), 21.8 in Spain (10), 23.2 in Norway (27), and 24.7 in Australia (28) in the same age group. The missed teeth component of the (DMFT) was the highest as compared to decayed and filled components. Same findings were also reported in Belgium (26) and in Spain (10). Moreover, the prevalence and the severity of untreated decay reported in this study are within the range of that reported around the world from $43.1-98.0 \%(4,6,10,27,29)$. Although D-component was high in this study, the prevalence and number of filled teeth were lower and extremely lesser than that reported in other studies ranging from $31.9 \%(6)$ to $40 \%(26)$. While other studies reported a mean number of filled teeth, Sudan (0.2) (23), China (0.49) (29) and in Singapore (0.25) (30), that is comparable to that reported in this study. This study showed lower prevalence of edentulism (5.2\%) compared to a range between $23.5 \%$ and $88 \%$ reported around the world $(5,6,10,14,26-28,30-32)$. This difference may be due to the older age groups investigated in these studies $(6,13,26,28,31,32)$, as the prevalence of total tooth loss peak at 75 to 79 years old (33). Also, most of those participants were living in institutional houses $(5,6,27,28,32)$ or were medically compromised, physically disabled, or cognitively impaired $(26,31)$ which can result in a decline of oral health due to poor oral hygiene and missing regular dental check-ups.

The prevalence of decayed and filled teeth in this study were significantly higher in younger age-group (60-69 years old) which is in contrast with other studies around the world $(6,30)$, but Khalifa, N. et al (23) reported the same pattern of decay among Sudanese adults which was less prevalent in older than younger age groups. This fact should be looked at together with the prevalence of missing teeth in this study. Older participants, although not statistically significant, had higher number of missing teeth, which indicates that diseased teeth had been extracted at some point. The same concept can be applied on the effect of oral hygiene on decayed and filled teeth, where participants with adequate oral hygiene practices retain natural teeth longer, but these retained teeth are exposed more to oral diseases.

In this study, being female was associated with increased severity of decayed, missed, filled teeth and high (DMFT). This was in accordance with the results of Gao, $\mathrm{Y}$ et al (29) where poorer oral health was observed in females (29). In contrast, another study (6) reported that males had more decayed teeth, higher need for extraction and total treatment needs, while females had more fillings. This study showed an association between the severity of decay and high (DMFT) with good general health which is in contrast with the findings of previous studies that suggested some chronic diseases such as cardiovascular disease, asthma and epilepsy increased the risk of developing dental caries (34). One possible explanation was reported by Saunders, R and Friedman, B (31) where perceived good general hatural teeth, but the study has no reference to the condition 
of the retained teeth. Other possible explanation might be that the data regarding chronic diseases and use of medications in this study were self-reported and they may have been subjected to recall bias or false reporting.

This study showed that the patterns of utilization of dental services affect the prevalence and severity of decayed teeth, severity of missed teeth and overall (DMFT), which gives an indication of the types and availability of dental services provided in Khartoum state. The increased number of untreated decayed teeth and low number of filled teeth accompanied with high number of missed teeth indicated the presence of barriers to access dental services for most of the population, and those with access had extraction as the choice of treatment. The importance of regular dental visits to improve oral health was emphasized recently in a system dynamic model of Thai adults and elderly(35). The model showed high improvement in dental caries status with the application of health promotion programs and increase affordability and capacity of dental health services (35). The barriers to access dental services include the availability of dental services. The health care delivery system in Sudan is based on governmental facilities (primary health care centers and hospitals) and private practices, with density of 2.1 dentist per 10000 population(36). Other factors that limits older persons' access to dental care are related to transportation problems (17), lack of perceived need for the visit (31), and unaffordability of dental services (19).

The modified (CPI) was used in this study because of its ability to differentiate between gingival inflammation and periodontal destruction, and because it allows for examination of all present teeth instead of using index teeth, which may over or under estimate the periodontal condition $(33,37)$. Using the modified (CPI) may make the comparison of the finding of this study with other studies using different indices difficult. The reported prevalence of periodontal pockets was lower than the $65 \%$ reported in Norway (27), 87\% in Belgium (26), and $96.1 \%$ in Japanese populations (37). While prevalence of gingival inflammation and attachment loss were more than that reported in other surveys (28)' (37). The prevalence of loss of attachment in this study was associated with aging, similar to what was reported by Sekino, S et al (37), while Mei Na T et al (30) found that age was not associated with the incidence of periodontal diseases.

The prevalence of mucosal lesions in this study was lower than that reported in older adults around the world ranging from $18.2-64 \%(10,26,28,38)$. The pathological origin of oral lesions reported differed per geographic regions, communities and oral status. Some studies reported that the majority of oral mucosal lesions among elderly were associated with denture trauma and candida infection $(10,26,28)$ while others associated to tobacco use (38). In this study, tobacco was the strongest risk factor of developing oral mucosal lesion. This finding is in accordance with the finding of Patil S. et al (38).

There are limited number of studies that investigated tooth wear among older adults using varied criteria to classify tooth wear, which make comparison of the results difficult. The prevalence of tooth wear in this study associated with poor socioeconomic status while the severity associated with poor perceived 
oral health. the same was reported among Dutch adults, where participants with low socioeconomic status had higher score of tooth wear (8).

The prevalence of using removable dentures was compatible with that reported previously in Sudanese adults, where few participants wearing either fixed bridges or removable dentures (39). While being low compared to complete dentures users reported in different parts of the world that ranged from $12-89 \%$ $(5,6,27,32)$. The prosthetic status associated with less frequent dental visits for routine check-up and treatment, the same finding was reported by The Spanish Geriatric Oral Health Research Group (10). Despite the low prevalence of using dentures, this study found high prevalence of prosthetic needs among the participants. The prevalence of prosthetic needs and the need for complete denture treatment associated with females, poor oral hygiene practices and perceived poor oral health. Participants visiting dentists due to pain had higher prevalence of prosthetic treatment needs, while those visited dentists for routine check-up or treatment needed more complete dentures.

Some of the previously reported predictors of poor oral health such as older age $(6,26)$, low socioeconomic status $(39,40)$, smoking and using smokeless tobacco and alcohol consumption $(37,41)$ were found to have no effect on oral health status in this study. This can be attributed to factors such as the participants investigated in this study had a close age range that did not allow for detection of oral health variations. This study was conducted among patients attending primary health care centers, which mainly are attended by low-income population who cannot afford private practice. That would increase the possibility of excluding high socioeconomic individuals. The fact that the data regarding tobacco use and alcohol consumption were self-reported and the small number of users among the participants, with no consideration of previous users, may resulted in insufficient power to detect a significant association. One limitation of the study is that the sample size was calculated for estimating the prevalence of dental caries. It was not to elicit various associations; a larger sample size would have been required to establish these associations adequately. A better approach to conduct the survey would have been a household survey to reduce the bias of excluding older adults with no health conditions, those with limiting mobility who cannot reach primary health care centers, and socioeconomically advantaged individuals. Moreover, self-reported information may be subjected to information bias such as recall bias or false reporting affected by social desirability.

\section{Conclusion}

Despite the low level of edentulism, the oral health of old adults of the studied Sudanese population is poor. They showed high prevalence and severity of missed and decayed teeth, periodontal inflammation and prosthetic treatment needs. Gender, perceived oral health, frequency and reason of dental visits were the most important predicting variables for most oral health outcomes.

\section{Abbreviations}


Decayed, Missed, Filled teeth (DMFT), World health organization (WHO), University of science and technology (UST), Community periodontal index (CPI), Intra-class correlation (ICC), Odds Ratios (OR), Confidence Interval $(\mathrm{Cl})$.

\section{Declarations}

Ethics approval and consent to participate: The study received ethical approval from the University of Science and Technology (UST), Omdurman, Sudan and the Management of Innovation, Development and Scientific Research, Ministry of Health (NO: UST/FD/ERC. 20.8.2018). All participants signed an informed consent form before the beginning of the data collection. All methods were carried out in accordance with the guidelines and regulations of the University of Science and Technology (UST).

Consent for publication: The authors have agreed on the content of the manuscript.

Availability of data and materials: The data collection tools and datasets generated and/or analyzed during the current study are available from the corresponding author on reasonable request.

Competing interests: The authors declare that they have no competing interests.

Funding: No funding was obtained for the study.

Authors' contributions: MAS, RWA, EFN were responsible for the study design, analyses, interpretation of data, and drafts of the manuscript. MAS was responsible of data collection. All authors have read and approved the final manuscript.

Acknowledgements: We acknowledge the contributions of University of Science and Technology and the Health Care Centers, Ministry of Health, Khartoum State, Sudan for providing facilities to the study.

Authors' information:1 Lectures, Department of Prosthetic Dentistry, Faculty of Dentistry, University of Science and Technology, Omdurman, Sudan. 2 Professor of Periodontology, Faculty of Dentistry, University of Science and Technology, Omdurman, Sudan. 3 Associate professor, Preventive Department, College of Dentistry, King Faisal University, Alahsa, KSA.

\section{References}

1. United Nation, Department of Economic and Social Affairs, Population Division. World Population Ageing. 2015; 9-39.

2. Petersen PE, Yamamoto T. Improving the Oral Health of Older People: The Approach of The WHO Global Oral Health Programme. Community Dent Oral Epidemio. 2005; 33(2):81-92.

3. WHO. Active Ageing: A Policy Framework. 2002; 1-41 p.

4. Zhang J, Leung K, Chu C, Lo E. Risk indicators for root caries in older adults using long-term social rare farilities in Honn Konn rommunity Dent Oral Epidemiol. 2020; 48:14-20. 
5. Shenoy RP, Hegde V. Dental Prosthetic Status and Prosthetic Need of the Institutionalized Elderly Living in Geriatric Homes in Mangalore: A Pilot Study. ISRN Dent. 2011; doi:10.5402/2011/987126.

6. Janssens B, Vanobbergen J, Petrovic M, Jacquet W, Schols JMGA, De Visschere L. The Oral Health Condition and Treatment Needs of Nursing Home Residents in Flanders (Belgium). Community Dent Health. 2017; 34:143-51.

7. Turner M, Ship J. Dry Mouth and its Effects on the Oral Health of Elderly People. J Am Dent Assoc. 2007; doi.org/10.14219/jada.archive.2007.0358.

8. Wetselaar P, Vermaire JH, Visscher CM, Lobbezoo F, Schuller AA. The Prevalence of Tooth Wear in the Dutch Adults Population. Caries Res. 2016;50(6):543-50.

9. Mesas A, Andrade SD, Cabrera M, Bueno V. Oral Health Status and Nutritional Deficit in Noninstitutionalized Older Adults in Londrina, Brazil. Rev Bras Epidemiol. 2010;13(3):434-5.

10. The Spanish Geriatric Oral Health Research Group. Oral Health Issues of Spanish Adults Aged 65 and Over. Int Dent J. 2001; 51:228-34.

11. Mummolo S, Ortu E, Necozione S, Monaco A, Marzo G. Relationship Between Mastication and Cognitive Function in Elderly in L'Aquila. Int J Clin Exp Med. 2014;7 (4): 1040-46.

12. Listl S. Oral Health Conditions and Cognitive Functioning in Middle and Later Adulthood. BMC Oral Health. 2014;14: 70.

13. Castrejón-Pérez RC, Borges-Yáñez SA, Gutiérrez-Robledo LM, Ávila-Funes JA. Oral Health Conditions and Frailty in Mexican Community-Dwelling Elderly: A Cross Sectional Analysis. BMC Public Health. 2012;12: 773.

14. Shimazaki Y, Soh I, Saito T, Yamashita Y, Koga T, Miyazaki H, et al. Influence of Dentition Status on Physical Disability, Mental Impairment, and Mortality in Institutionalized Elderly People. J Dent Res. 2001;80(1):340-5.

15. Hägglund P, Koistinen S, Olai L, Ståhlnacke K, Wester P, Levring Jäghagen E. Older People with Swallowing Dysfunction and Poor Oral Health are at Greater Risk of Early Death. Community Dent Oral Epidemiol. 2019; 47:494-501.

16. Shay K. Infectious Complications of Dental and Periodontal Diseases in the Elderly Population. Clin Infect Dis. 2002; 34(9):1215-23.

17. Dolan TA. Access to Dental Care Among Older Adults in the United States. J Dent Educ. 2005;69(9):14.

18. Gulcan F, Ekback G, Ordell S, Lie S, Astrom A. Inequalities in Oral Health Related to Early and Later Life Social Conditions: A Study of Elderly in Norway and Sweden. BMC Oral Health. 2015; DOI 10.1186/s12903-015-0005-y.

19. Petersen P, Kandelman D, Arpin S, Ogawa H. Global Oral Health of Older People- Call for Public Health Action. Community Dent Health. 2010;27(Supplement 2):257-68.

20. Bassim C, MacEntee M, Nazmul S. Self-reported Oral Health at Baseline of the Canadian Lonaitudinal Studv on Aqinq. Community Dent Oral Epidemiol. 2020; 48:72-80.

Loading [MathJax]/jax/output/CommonHTML/jax.js

Page $21 / 23$ 
21. United Nation, Department of Economic and Social Affairs, Population Division. World Population Prospects 2019. 2019. https://population.un.org/wpp/. Accessed April 2020.

22. Central Bureau of Statistics Republic of Sudan. The Total Population Expected to States for the Period 2009-2018. 2013. http://www.cbs.gov.sd/en/files.php?id=7\#\&panel1-1. Accessed July 2018.

23. Khalifa N, Allen PF, Abu-bakr NH, Abdel-Rahman ME, Abdelghafar KO. A Survey of Oral Health in a Sudanese Population. BMC Oral Health. 2012;12(5).

24. World Health Organization. Oral Health Surveys Basic Methods. 5TH ed. WHO Press; 2013.

25. World Health Organization, Central Bureau of Statistics Republic of Sudan, Federal Ministry of Health (Sudan). SUDAN STEPwise SURVEY FOR NON-COMMUNICABLE DISEASES RISK FACTORS 2016 REPORT. 2016.

26. De Visschere L, Janssens B, De Reu G, Duyck J, Vanobbergen J. An Oral Health Survey of Vulnerable Older People in Belgium. Clin Oral Investig. 2016;20(8):1903-12.

27. Samson H, Strand GV, Haugejorden O. Change in Oral Health Status Among the Institutionalized Norwegian Elderly Over a Period Of 16 Years. Acta Odontol Scand. 2008;66(6):368-73.

28. Stubbs C, Riordan P. Dental Screening of Older Adults Living in Residential Aged Care Facilities in Perth. Aust Dent J. 2002;47(4):321-6.

29. Yi Bo G, Tao H, Xue Dong Z, Rui S, Ran C, Guo Song W, et al. Dental Caries in Chinese Elderly People: Findings from the 4th National Oral Health Survey. Chin J Dent Res. 2018;21(3):213-20.

30. Mei Na T, Nair R, Di Ying JN, Yee R. Oral Health Status and Complete Denture Status of IndependentLiving Singaporean Elderly Residing in a Community Home. Singapore Dent J. 2014; 35:9-15.

31. Saunders R, Friedman B. Oral Health Conditions of Community-Dwelling Cognitively Intact Elderly Persons with Disabilities. Gerodontology. 2007; 24:67-76.

32. Hoeksema AR, Peters LL, Raghoebar GM, Meijer HJA, Vissink A, Visser A. Oral Health Status and Need for Oral Care of Care-Dependent Indwelling Elderly: From Admission to Death. Clin Oral Investig. 2017;21(7):2189-96.

33. Kassebaum NJ, Smith A, Bernabé E, Fleming TD, Reynolds AE, Vos T, et al. Global, Regional, and National Prevalence, Incidence, and Disability- Adjusted Life Years for Oral Conditions for 195 Countries, 1990-2015: A Systematic Analysis for the Global Burden of Diseases, Injuries, and Risk Factors. J Dent Res. 2017;96(4):380-7.

34. Gati D, Vieira AR. Elderly at Greater Risk for Root Caries: A Look at the Multifactorial Risks with Emphasis on Genetics Susceptibility. Int J Dent. 2011; doi:10.1155/2011/647168.

35. Urwannachotima N, Hanvoravongchai P, Ansah JP, Prasertsom P. System Dynamics Analysis of Dental Caries Status Among Thai Adults and Elderly. J Health Res. 2020;34(2):134-46.

36. World Health Organization. World health statistics overview 2019: Monitoring Health for the SDGs, Sustainable Development Goals. Geneva: (WHO/DAD/2019.1); 2019.

37. Sekino S, Takahashi R, Numabe Y, Okamoto H. Current Status of Periodontal Disease in Adults in Takahani Ianan. $\Delta$ rrncc-Sertinnal Stydy. BMC Oral Health. 2020;20(60). 
38. Patil S, Doni B, Maheshwari S. Prevalence and Distribution of Oral Mucosal Lesions in a Geriatric Indian Population. Can Geriatr J. 2015;18(1).

39. Khalifa N, F. Allen P, H. Abu-bakr N, E. Abdel-Rahman M. Factors Associated with Tooth Loss and Prosthodontic Status Among Sudanese Adults. J Oral Sci. 2012; 54(4):303-12.

40. Astrom A, Ekback G, Ordell S, Nasir E. Long-term Routine Dental Attendance: Influance on Tooth Loss and Oral Health-Related Quality of Life in Swidish Older Adults. Community Dent Oral Epidemiol. $2014 ; 42: 460-9$.

41. World Dental Federation. The Challenge of Oral Disease - A Call for Global Action. The Oral Health Atlas. 2nd ed. Geneva; 2015. 